\title{
Study the Attenuation Coefficient of Granite to Use It as Shields against Gamma Ray
}

\author{
Laith Ahmed Najam1 ${ }^{*}$, Abdalsattar Kareem Hashim², Hussein Abdulkareem Ahmed ${ }^{3}$, \\ Israa M. Hassan ${ }^{1}$ \\ ${ }^{1}$ Department of Physics, College of Science, University of Mosul, Mosul, Iraq \\ ${ }^{2}$ Department of Physics, College of Science, Kerbala University, Kerbala, Iraq \\ ${ }^{3}$ Department of Physics, Faculty of Science, University of Zakho, Duhok, Iraq \\ Email: "prof.lai2014@gmail.com
}

Received 26 January 2016; accepted 22 March 2016; published 25 March 2016

Copyright (C) 2016 by authors and Scientific Research Publishing Inc.

This work is licensed under the Creative Commons Attribution International License (CC BY).

http://creativecommons.org/licenses/by/4.0/

c) (i) Open Access

\begin{abstract}
The present work investigates the linear and mass attenuation coefficients for gamma rays practically and theoretically by using spectroscopy gamma ray (UCS-20) and program (XCOM)) for various types of common use granite, and compares them with the lead because of its high blocking ability for this type of radiation. This paper concluded through linear and mass attenuation coefficients measurements that these coefficients decrease with increasing incident photons energy. Measurements also showed that the linear attenuation coefficients appropriate linearly with density while mass attenuation coefficients do not get affected.
\end{abstract}

\section{Keywords}

Gamma Rays, Attenuation Coefficient (Linear and Mass), Building Materials, Sodium Iodide Detector

\section{Introduction}

It is well known that all the benefit of the using ionizing radiation could accrue to human being as a result. Exposure to this radiation is held according to the damage that results from it making man takes a negative attitude from all nuclear applications and even peaceful ones since everything that exists on the surface of the ground is exposed to the effect of ionizing radiation, like the cosmic radiation and radioactive materials in the ground or industrial sources used for medical purposes. However, depending on intensive studying of the results of nuclear experiment, these harms could be reduced to be equal with the damages caused by any technological or other industrial process. There are many ways to control the external exposure to radiation and reduce it to the mini-

*Corresponding author. 
mum levels. The covers or protective shields are particularly used for this purpose, and despite the fact that there are different materials used for shielding, lead is widely used because it has high reserve force that helps to reduce the thickness of the armors manufactured from which. Because of the breadth of the required areas to be protected especially in cases designing armors in hospitals, clinics and nuclear institutions, the use of lead is expensive and so concrete where other building materials are used to increase the thickness of the protective walls [1].

Therefore, researches and studies are conducted to design shields to protect from gamma rays that have high-penetration capability by discovering the attenuation coefficients for each material and to state its ability to block these rays. The attenuation coefficient of the gamma rays is measured with energies (295.2, 351.9, 583.1, 609.3, 911.1, 1460.8) keV for some building materials used in Jordan like ceramic, alabaster, granite, bricks, concrete and limestone by the researcher Awadallah et al. [2] and they find that among the selected samples, the granite is the best protective armor against radiation with linear attenuation coefficient $(29.2 \pm 0.9) \mathrm{m}^{-1}$ at energy $(295.2 \mathrm{keV})$ for gamma rays.

Also the researchers Mortazavi et al., [3] use different samples of concrete after being treated with high metals density (colemanite and galena) as a shield of photons of high energy using package of gamma emitted from ${ }^{60} \mathrm{Co}$. In this research, effective and economical armor is produced to protect from gamma ray in high-energy atomic radiation rooms and nuclear power plants.

Cevik et al. [4] study the natural radiation and the coefficient of attenuation mass for 107 different Marble sample in Turkey where they find that the experimental values are consistent with the theoretical values.

The researchers Akkurt et al. [5] conduct a study the linear attenuation coefficient for the samples of concrete containing Zeolite with different concentrations of $(0 \%, 10 \%, 30 \%$, and $50 \%)$. It is noted that the linear attenuation coefficient decreases with increasing concentration of Zeolite, and it is concluded that Zeolite is nonconvenient to use as a protective shield from radiation.

Also the shield made from (Amethyst ore) is compared with shield made of concrete by researchers Korkt $e t$ al. [6]. It is found that the shield (Amethyst ore) has more absorbency ability for gamma rays than concrete at the same gamma ray energy. Moreover, Damla et al., [7] study the attenuation coefficients of gamma rays practically and theoretically in the number of materials such as sand, cement, bricks, tiles and other building material which used in Turkey, at range of gamma ray energy $(81$ - 1332) keV and they find that the cement is the most perfect armor visor radiation with mass attenuation coefficient $\left(0.252 \mathrm{~cm}^{2} / \mathrm{g}\right)$.

The aim of this research is to study the linear and mass attenuation coefficients of gamma rays practically and theoretically using spectroscopy gamma ray (UCS-20) and by using program (XCOM)) for various types of common use granite, and compare them with the lead because it's high blocking ability for this type of radiation.

\section{Theoretical Part}

When parallel bundle of gamma rays falls on the absorbed material, a photon will emit and interact with one of the material atoms in any of the three processes from the package by fully absorbing the energy and disappearing (through the processes of the photoelectric effect or the pair production or because of the dispersion or deviation from its path (Compton effect)). Thus, the number of photons $(d n)$ that emits from of the package proportionate directly with the number of photons falling $\left(n_{0}\right)$ and with the thickness of the attenuated material. Generally, the intensity of radiation is used instead of the number of photons $n$.

So the equation is written as following:

$$
I=I_{o} \exp (-\mu x)
$$

$I_{o}$ : intensity of incident radiation on the article.

I: The intensity of the rays which penetrates thickness of the material $(x)$ and does not include any secondary radiation that may cause by the interaction inside this thickness [8]. The amount exp $(-\mu x)$ represents the possibility of cutting the photon distance $(x)$ within the media which attenuates the rays without interaction. If $\left(I_{o}>I\right)$, that means the bundle suffers an exponential decreasing and its intensity value is $(\mu)$ along the distance. Therefore, the $(\mu)$ can be calculated from the relationship (1) to be as follows:

$$
\mu=\ln A / x
$$

A: Attenuation ratio $\left(I_{o} / I\right)[9]$. 
But if there is no good geometrical arrangement when the fall of the gamma-ray is on the shield of certain thickness, the source radiates in all directions [10] [11].

$$
I=I_{o} B \exp (-\mu x)
$$

B: Accumulation factor

To get rid of the accumulation factor and to achieve exponential attenuation law in equation (1), a narrow beam of gamma rays should be used by using the shooting [12]. The attenuation coefficient $(\mu)$ is associated with the number of atoms in $1 \mathrm{~cm}^{3}$ of absorbed matter and whole cross-section $(E) \sigma$ of the interaction of photons with matter.

$$
\mu_{(E)}=n \sigma_{(E)}
$$

In other words, the linear attenuation coefficient is multiplied by the number of atoms in $1 \mathrm{~cm}^{3}$ of the matter in the whole cross-section $\sigma_{(E)}$ at a certain energy $E$.

\section{Practical Part}

Gamma rays sources $\left({ }^{60} \mathrm{Co},{ }^{137} \mathrm{Cs},{ }^{133} \mathrm{Ba}\right)$ and a system of gamma ray measurement (UCS-20) connected with the scintillation detector $\mathrm{NaI}(\mathrm{Tl})$ are used as shown in Figure 1. This system consists of a primary amplifier, major amplifier, voltage supply, and multi-channel analyzer. It is connected with a computer for the purpose of operating and reading the measurements and analyzing the results. A narrow beam of gamma rays is obtained by using a shooter lead of cylinder shape of a height $7 \mathrm{~cm}$ and a diameter of $5 \mathrm{~cm}$, containing a slot of diameter of 3.5 $\mathrm{mm}$ through which the radiation, coming from the radioactive source, passes.

\section{Results and Discussion}

The linear and mass attenuation coefficients are measured practically by using gamma ray system (UCS-20) where the Table 1 and Table 2 describe these results, which confirm that the attenuation coefficient increases linearly with density whereas mass attenuation coefficient remains constant with the density. Also the attenuation coefficients are calculated theoretically by using the program (XCOM) as shown in Table 3 and Table 4 and it is noted that if comparing the practical and theoretical values, there is a coincidence between these values, especially at high energies. The reason behind the significant difference between practical and theoretical at the low energy belongs to the Compton dispersion. The current study shows that the attenuation coefficients depend on the density of matter and the atomic number of the elements. So lead is preferred in shielding against gamma rays because it has high density and its atomic number is large.

Also the relationship between attenuation coefficients and the energies is shown in Figure 2.

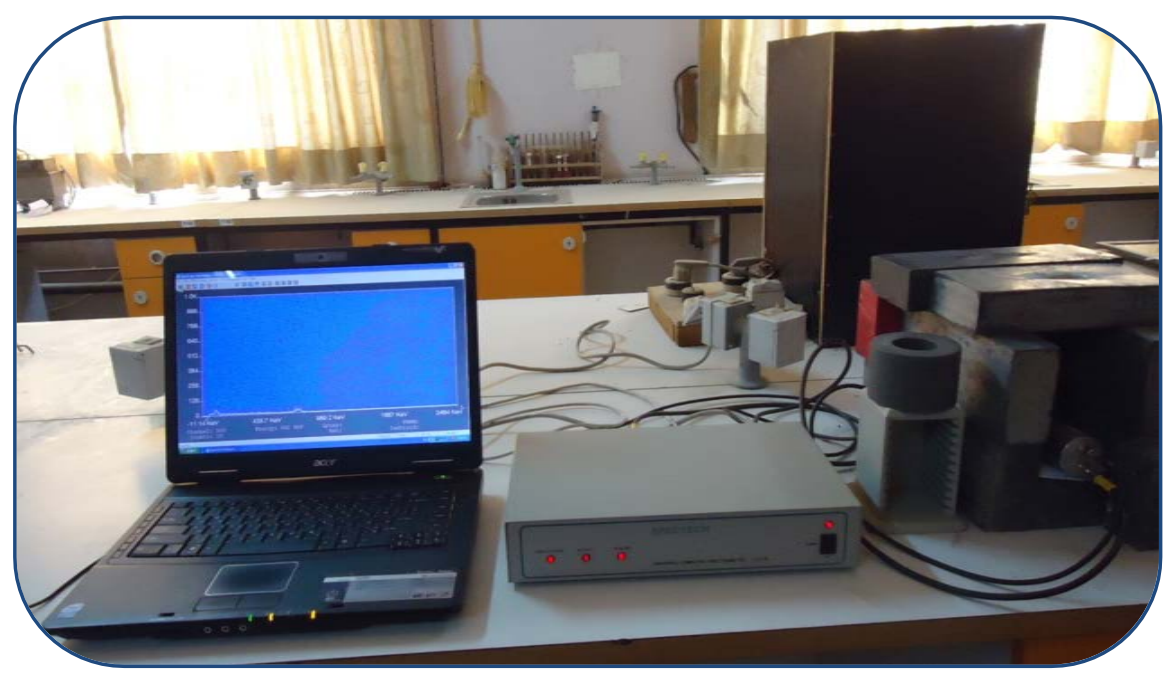

Figure 1. Photographic picture of system measurement. 
Table 1. The linear attenuation coefficients $\left(\mu\left(\mathrm{cm}^{-1}\right)\right)$ for various energies of the gamma rays experimentally.

\begin{tabular}{lcccccc}
\hline & Samples & $\mathbf{8 1}(\mathbf{k e V})$ & $\mathbf{3 5 6}(\mathbf{k e V})$ & $\mathbf{6 6 2}(\mathbf{k e V})$ & $\mathbf{1 1 7 3}(\mathbf{k e V})$ & $\mathbf{1 3 3 2}(\mathbf{k e V})$ \\
\hline $\mathbf{1}$ & Yellow Iraqi granite & $0.438 \pm 0.028$ & $0.241 \pm 0.012$ & $0.206 \pm 0.014$ & $0.118 \pm 0.011$ & $0.113 \pm 0.012$ \\
$\mathbf{2}$ & Orange Spanish granite & $0.500 \pm 0.0071$ & $0.239 \pm 0.012$ & $0.209 \pm 0.013$ & $0.012 \pm 0.130$ & $0.132 \pm 0.0112$ \\
$\mathbf{3}$ & Red Indian granite & $0.450 \pm 0.0064$ & $0.264 \pm 0.020$ & $0.198 \pm 0.011$ & $0.119 \pm 0.010$ & $0.115 \pm 0.012$ \\
$\mathbf{4}$ & Grey Chinese granite & $0.463 \pm 0.017$ & $0.238 \pm 0.013$ & $0.202 \pm 0.019$ & $0.120 \pm 0.017$ & $0.110 \pm 0.0091$ \\
$\mathbf{5}$ & Colored Egyptian granite & $0.446 \pm 0.0106$ & $0.244 \pm 0.010$ & $0.208 \pm 0.014$ & $0.129 \pm 0.013$ & $0.116 \pm 0.0099$ \\
$\mathbf{6}$ & White Turkish granite & $0.387 \pm 0.013$ & $0.253 \pm 0.017$ & $0.218 \pm 0.0088$ & $0.130 \pm 0.011$ & $0.125 \pm 0.020$ \\
$\mathbf{7}$ & Lead & --------- & --------- & $1.04 \pm 0.079$ & $0.729 \pm 0.057$ & $0.695 \pm 0.095$ \\
\hline
\end{tabular}

Table 2. The mass attenuation coefficients $\left(\mu / \rho\left(\mathrm{cm}^{2} / \mathrm{g}\right)\right)$ experimentally for different energies of gamma rays.

\begin{tabular}{lcccccc}
\hline & Samples & $\mathbf{8 1}(\mathbf{k e V})$ & $\mathbf{3 5 6}(\mathbf{k e V})$ & $\mathbf{6 6 2}(\mathbf{k e V})$ & $\mathbf{1 1 7 3}(\mathbf{k e V})$ & $\mathbf{1 3 3 2}(\mathbf{k e V})$ \\
\hline $\mathbf{1}$ & Yellow Iraqi granite & $0.162 \pm 0.0011$ & $0.089 \pm 0.0045$ & $0.074 \pm 0.0052$ & $0.043 \pm 0.0044$ & $0.042 \pm 0.0046$ \\
$\mathbf{2}$ & Orange Spanish granite & $0.187 \pm 0.0027$ & $0.089 \pm 0.0048$ & $0.078 \pm 0.0050$ & $0.048 \pm 0.0048$ & $0.049 \pm 0.0044$ \\
$\mathbf{3}$ & Red Indian granite & $0.201 \pm 0.0024$ & $0.098 \pm 0.0077$ & $0.073 \pm 0.0041$ & $0.044 \pm 0.0038$ & $0.042 \pm 0.0047$ \\
$\mathbf{4}$ & Grey Chinese granite & $0.174 \pm 0.0064$ & $0.089 \pm 0.0051$ & $0.076 \pm 0.0072$ & $0.045 \pm 0.0065$ & $0.041 \pm 0.0034$ \\
$\mathbf{5}$ & Colored Egyptian granite & $0.170 \pm 0.0041$ & $0.093 \pm 0.0040$ & $0.079 \pm 0.0053$ & $0.049 \pm 0.0050$ & $0.044 \pm 0.0034$ \\
$\mathbf{6}$ & White Turkish granite & $0.143 \pm 0.0048$ & $0.094 \pm 0.0063$ & $0.081 \pm 0.0032$ & $0.048 \pm 0.0043$ & $0.044 \pm 0.0074$ \\
$\mathbf{7}$ & Lead & -------- & --------- & $0.091 \pm 0.0070$ & $0.064 \pm 0.0050$ & $0.061 \pm 0.0084$ \\
\hline
\end{tabular}

Table 3. The linear attenuation coefficient $\left(\mu\left(\mathrm{cm}^{-1}\right)\right)$ theoretically.

\begin{tabular}{lcccccc}
\hline & Samples & $\mathbf{8 1}(\mathbf{k e V})$ & $\mathbf{3 5 6}(\mathbf{k e V})$ & $\mathbf{6 6 2}(\mathbf{k e V})$ & $\mathbf{1 1 7 3}(\mathbf{k e V})$ & $\mathbf{1 3 3 2}(\mathbf{k e V})$ \\
\hline $\mathbf{1}$ & Yellow Iraqi granite & 0.650 & 0.263 & 0.201 & 0.153 & 0.145 \\
$\mathbf{2}$ & Orange Spanish granite & 0.670 & 0.268 & 0.203 & 0.155 & 0.145 \\
$\mathbf{3}$ & Red Indian granite & 0.680 & 0.270 & 0.205 & 0.156 & 0.145 \\
$\mathbf{4}$ & Grey Chinese granite & 0.641 & 0.265 & 0.201 & 0.151 & 0.143 \\
$\mathbf{5}$ & Colored Egyptian granite & 0.587 & 0.261 & 0.198 & 0.151 & 0.144 \\
$\mathbf{6}$ & White Turkish granite & 0.661 & 0.266 & 0.203 & 0.154 & 0.145 \\
$\mathbf{7}$ & Lead & ------- & ------- & 1.24 & 0.691 & 0.634 \\
\hline
\end{tabular}

Table 4. The mass attenuation coefficients $\left(\mu / \rho\left(\mathrm{cm}^{2} / \mathrm{g}\right)\right)$ theoretically.

\begin{tabular}{|c|c|c|c|c|c|c|}
\hline & Samples & 81 (keV) & 356 (keV) & 662 (keV) & $1173(\mathrm{keV})$ & 1332 (keV) \\
\hline 1 & Yellow Iraqi granite & 0.242 & 0.099 & 0.075 & 0.057 & 0.054 \\
\hline 2 & Orange Spanish granite & 0.252 & 0.101 & 0.0766 & 0.058 & 0.054 \\
\hline 3 & Red Indian granite & 0.254 & 0.101 & 0.076 & 0.058 & 0.054 \\
\hline 4 & Grey Chinese granite & 0.242 & 0.100 & 0.076 & 0.057 & 0.054 \\
\hline 5 & Colored Egyptian granite & 0.225 & 0.100 & 0.076 & 0.058 & 0.054 \\
\hline 6 & White Turkish granite & 0.246 & 0.099 & 0.075 & 0.057 & 0.053 \\
\hline 7 & Lead & -------- & ------- & 0.110 & 0.061 & 0.056 \\
\hline
\end{tabular}




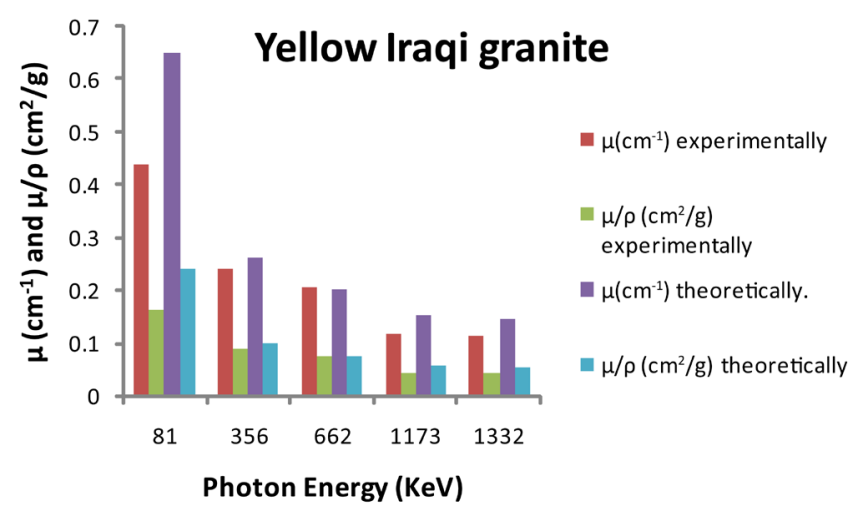

(a)

\section{Orange Espanish granite}

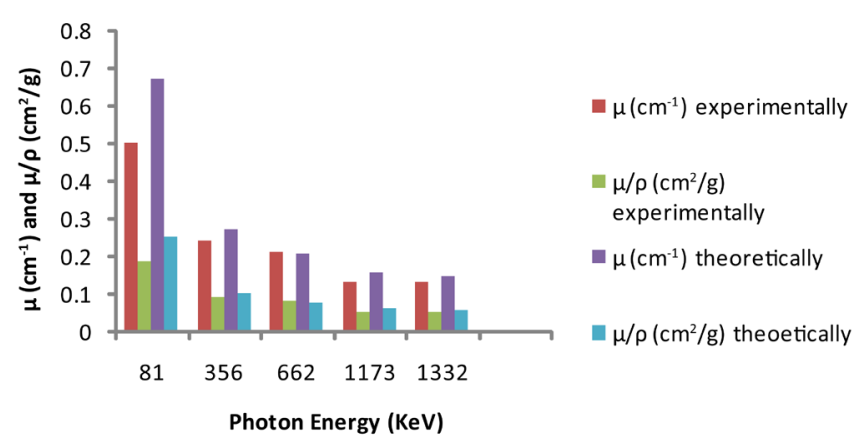

(b)

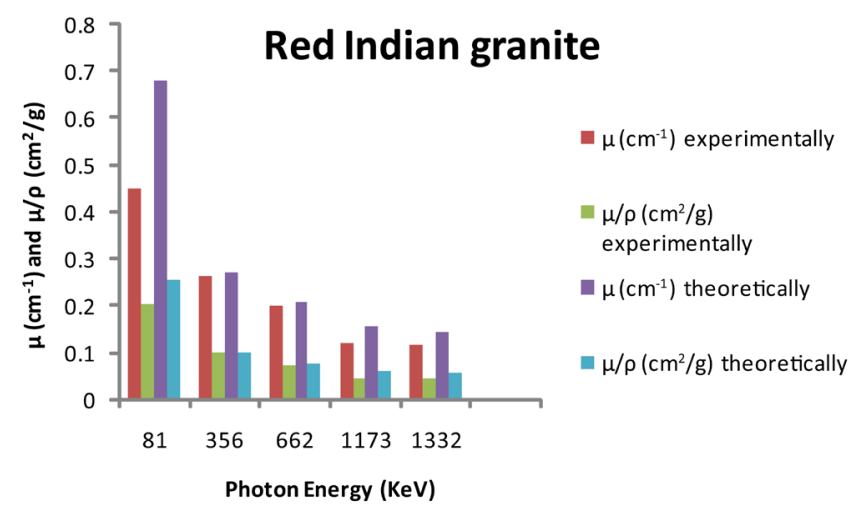

(c)

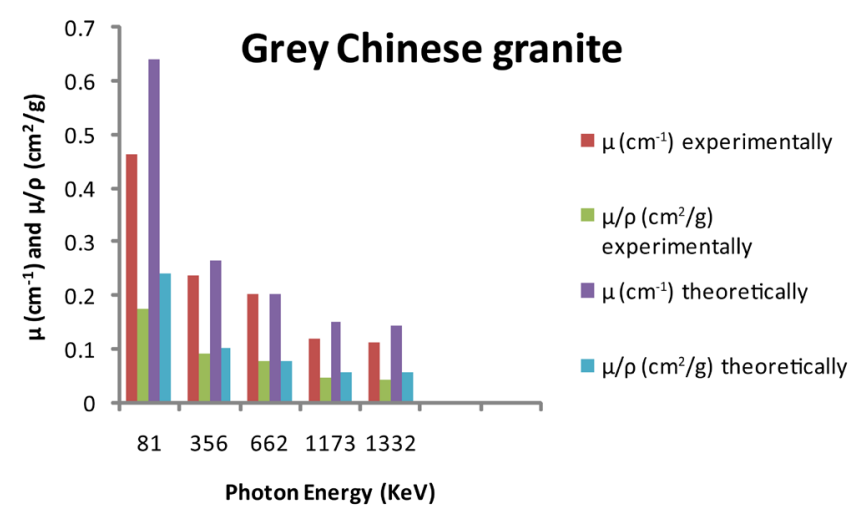

(d) 


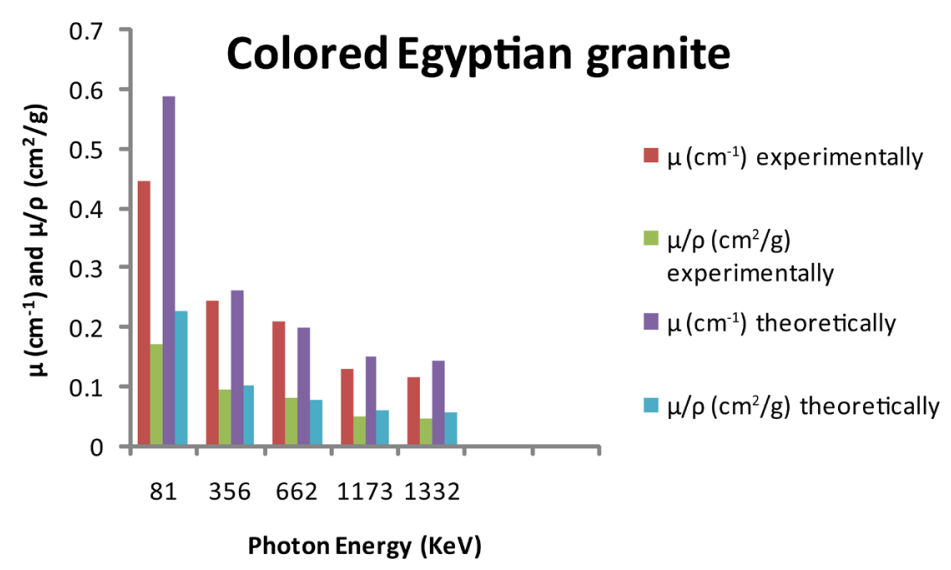

(e)

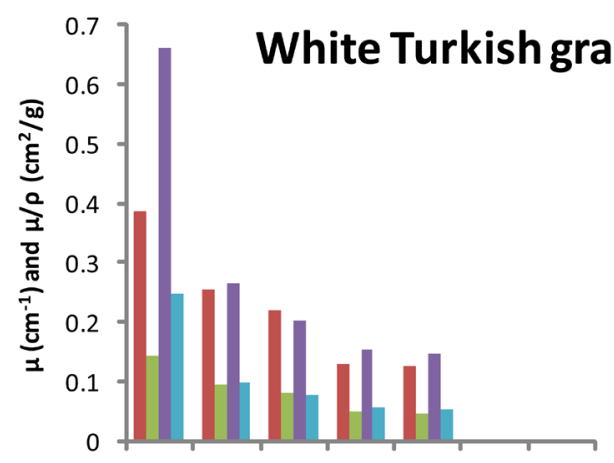

$81 \quad 356 \quad 66211731332$

Photon Energy (KeV)

(f)

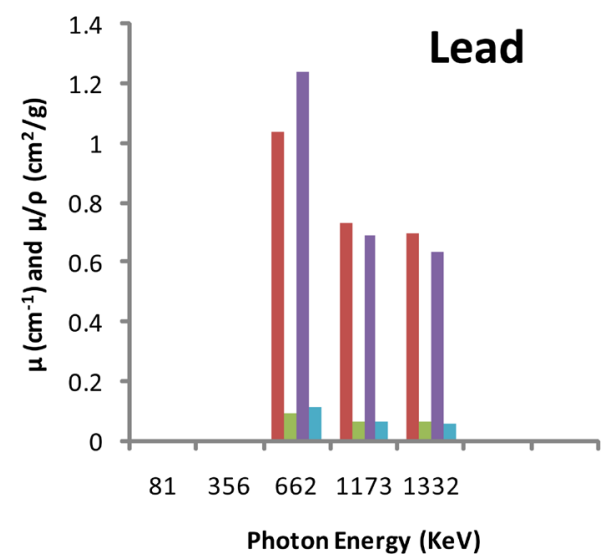

$\mu\left(\mathrm{cm}^{-1}\right)$ experimentally

$\mu / \rho\left(\mathrm{cm}^{2} / \mathrm{g}\right)$

experimentally

$\mu\left(\mathrm{cm}^{-1}\right)$ theoretically

$\mu / \mathrm{p}\left(\mathrm{cm}^{2} / \mathrm{g}\right)$ theoretically

(g)

Figure 2. (a)-(g) Shows the relation between linear and mass attenuation coefficients experimentally and theoretically with photon energy.

From the figures above, it is noted that the linear and mass attenuation coefficient decrease with increasing of incident photons energy and the reason for this is whenever the photons energy increases, the permeability will decrease and the ability of the matter for attenuation will decrease.

Figure above shows that among the materials which are under study, the Iraqi granite is one of the best materials being used in shielding compared to these made of the lead, therefore it is not preferable in shielding against gamma rays. 


\section{Conclusion}

It is concluded that through linear and mass attenuation coefficients measurements, these coefficients decrease with increasing incident photons energy. Measurements also show that the linear attenuation coefficients appropriate linearly with density while mass attenuation coefficients do not get affected. Moreover, this paper concludes that the matters which have the larger atomic number are the most efficient to attenuate the rays and consequently granite can be used as shields against gamma ray.

\section{References}

[1] Al-Ahmad, K.O. (1993) Introduction to Health Physics. National Library for Printing and Publishing, University of Mosul.

[2] Awadallah, M.I. and Imran, M.M. (2007) Radioactive Contents in Construction Materials Used in Jordanian Building. Dirasat, Pure Sciences, 34, 98-112.

[3] Mortazavi, S.M.J., Mosle-Shirazi, M.A., Roshanshomal, P., Raadpey, N. and Baradaran-Ghahfarokhi, M. (2010) High-Performance Heavy Concrete as a Multi-Purpose Shield. Radiation Protection Dosimetry, 142, 120-124.

[4] Cevik, U., Damla, N., Kobya, A.I., Celik, A. and Kara, A. (2010) Radiation Dose Estimation and Mass Attenuation Coefficients of Marble. Annals of Nuclear Energy, 37, 1705-1711. http://dx.doi.org/10.1016/j.anucene.2010.07.011

[5] Akkurt, I., Akyıldırıma, H., Mavi, B., Kilincarslan, S. and Basyigit, C. (2010) Radiation Shielding of Concrete Containing Zeolite. Radiation Measurements, 45, 827-830.

[6] Korkut, T., Korku, H., Karabulut, A. and Budak, G. (2011) A New Radiation Shielding Material: Amethyst Ore. Annals of Nuclear Energy, 38, 56-59. http://dx.doi.org/10.1016/j.anucene.2010.08.017

[7] Damla, B.H., Celik, A., Kırıs, E. and Cevik, U. (2012) Calculation of Radiation Attenuation Coefficient Affective Atomic Number and Electron Densities for some Building Materials. Radiation Protection Dosimetry, 150, 541-549.

[8] Muhammad, F.M. and Ghalib, A.M. (2008) Measure and Calculate the Linear and the Mass Attenuation Coefficient for X-Ray of the Wood Material. Thesis, Tikrit Magazine Pure Sciences 13 Folder, No. 1, 118-128.

[9] Profio, A.E. (1979) Radiation Shielding and Dosimeter. John Wiley and Sons, Inc., Hoboken.

[10] Ogundare, F.O., Ogundele, S.A., Akerele, O.O. and Balogun, F.A. (2012) Low-Energy Broad Beam Photon Shielding. Journal of Applied Clinical Medical Physic, 13, 176-182.

[11] Medhat, M.E. (2009) Gamma-Ray Attenuation Coefficients of Some Building Materials Available in Egypt. Annals of Nuclear Energy, 36, 849-852. http://dx.doi.org/10.1016/j.anucene.2009.02.006

[12] Mheemeed, A.K., Hasan, I.H. and Al-Jomaily, F.M. (2012) Gamma-Ray Absorption Using Rubber-Lead Mixtures as Radiation Protection Shields. Journal of Radioanalytical and Nuclear Chemistry, 291, 653-659.

http://dx.doi.org/10.1007/s10967-011-1556-2 